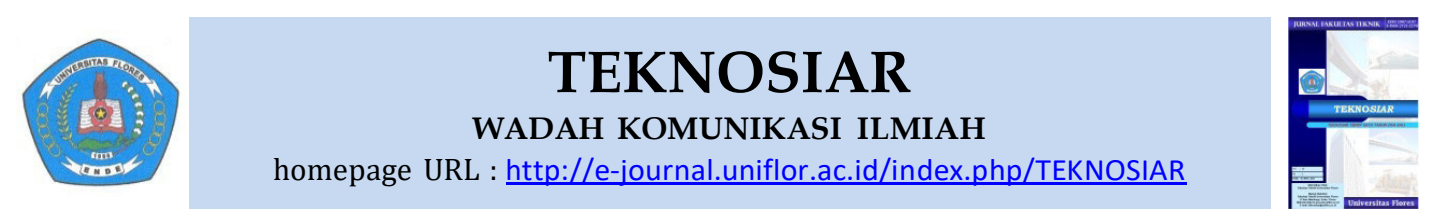

\title{
Pendekatan Arsitektur Tropis Pada Bangunan SMAK Syuradikara Ende
}

\author{
*Petrus Jhon Alfred Depa Dede', Silvester Masias Siso², Fabiola T.A. Kerong ${ }^{3}$. \\ 1,2,3 Program Studi Arsitektur Fakultas Teknik Universitas Flores, Ende \\ *) Correspondence e-mail: ff3redo@gmail.com
}

Received: 27-03-2020 Revised: 17-04-2020 Accepted: 20-04-2020

\begin{abstract}
ABSTRAC
Colonial buildings in Indonesia are a unique phenomenon, a mixture of cultures between colonizers and Indonesian culture that cannot be found anywhere else and adapted to the climatic conditions, namely the humid tropical climate. The city of Ende in the past was one of the destinations for traders and sailors from Java, Makassar and Ternate. Because it became a transit point for traders, religious history and colonialism interests played out in the port areas in Ende City. Buildings with historical value that still survive and have colonial architectural features in Ende City, one of which is the Syuradikara Catholic High School (SMAK) building, whose existence has unwittingly adapted to the tropical climate. To determine the extent to which tropical climatic conditions (tropical architectural approaches) can affect the design of the Syuradikara Catholic High School building in Ende City, the authors conducted a study. This study was conducted using descriptive qualitative methods. The approach to the tropical climate studied includes the orientation of the building, the openings and materials used. The descriptive qualitative method is used to describe the design elements of the Syuradikara Catholic High School building which are closely related to the tropical climate. In conducting this study data collection was carried out by interview, survey, observation and literature study. From the results of the study it was found that the orientation of the building as a whole faces and extends towards the north and south. The surface of the building facing the direction of coming and setting of the sun receives very little of the sun's heat. The wind flow around the building came from the east and west and the room that had good wind flow was the classroom. The orientation of the laying of the windows is predominantly facing north and south. The existence of terraces along the building is to anticipate direct sunlight hitting the walls of the building, and the impact of rainwater. Unpolished ceramic and tile floor material with a slightly rough surface so that it absorbs heat, the room tends to be cooler. The walls of the building are made of plastered bricks, the thickness of the walls is between 30 and 40 centimeters, so that it can reduce the hot air in the room.
\end{abstract}

Keywords: tropical architecture, syuradikara catholic high school, ende city

\section{ABSTRAK}

Bangunan kolonial di Indonesia merupakan fenomena yang unik, percampuran budaya antara penjajah dan budaya Indonesia yang tidak terdapat ditempat lain serta disesuaikan dengan kondisi iklimnya yaitu iklim tropis lembab. Kota Ende pada masa lalu menjadi salah satu daerah tujuan para pedagang dan pelayar dari Jawa, Makassar, dan Ternate. Karena menjadi salah satu titik transit para pedagang maka sejarah keagamaan dan kepentingan-kepentingan Kolonialisme bermain di daerah-daerah pelabuhan di Kota Ende. Bangunan bernilai sejarah yang masih bertahan dan memiliki ciri arsitektur kolonial di Kota Ende, salah satunya adalah bangunan Sekolah Menengah Atas Katolik (SMAK) Syuradikara, yang keberadaannya tanpa disadari beradaptasi dengan iklim tropis. Untuk mengetahui sejauh mana kondisi iklim tropis (pendekatan arsitektur tropis) dapat mempengaruhi desain bangunan SMAK Syuradikara di Kota Ende, maka penulis melakukan kajian. Kajian ini dilakukan dengan menggunakan metode kualitatif deskriptif. Pendekatan

TEKNOSIAR Volume 14, No.01, April 20

p-ISSN 1907-5197 (versi cetak) e-ISSN 2721-2270 (versi online) 
terhadap iklim tropis yang dikaji meliputi orientasi bangunan, bukaan dan material yang digunakan. Metode kualitatif deskriptif digunakan untuk menguraikan elemen desain bangunan SMAK Syuradikara yang berkaitan erat dengan iklim tropis. Dalam melakukan kajian ini pengumpulan data dilakukan dengan wawancara, survey, observasi dan studi literatur. Dari hasil kajian ditemukan bahwa orientasi bangunan secara keseluruhan menghadap dan memanjang kearah utara dan selatan. Permukaan bangunan yang menghadap arah datang dan terbenam matahari hanya sedikit yang menerima panas matahari. Aliran angin di sekitar bangunan datang dari arah timur dan barat dan ruangan yang mendapatkan aliran angin yang baik adalah ruang kelas. Orientasi peletakan jendela lebih dominan menghadap ke arah utara dan selatan. Keberadaan teras disepanjang bangunan untuk mengantisipasi sinar matahari langsung yang mengenai dinding bangunan, serta hempasan dari air hujan. Material lantai dari keramik dan tegel yang belum dipoles dengan permukaan sedikit kasar sehingga menyerap panas, ruangan cenderung lebih dingin. Dinding bangunan terbuat dari susunan bata yang diplester, tebal dinding antara 30 sampai 40 centimeter, sehingga dapat mereduksi udara panas yang ada dalam ruangan.

Kata Kunci : arsitektur tropis, sekolah menengah atas katolik syuradikara, kota ende

\section{PENDAHULUAN}

Kabupaten Ende adalah sebuah kabupaten di Pulau Flores Propinsi Nusa Tenggara Timur. Secara geografis Kabupaten Ende memiliki letak yang cukup strategis yaitu dibagian tengah Pulau Flores yang diapit oleh empat Kabupaten di bagian barat : Nagekeo, Ngada, Manggarai, dan Manggarai Barat, sedangkan dibagian timur dengan dua Kabupaten yakni : Kabupaten Sikka dan Kabupaten Flores Timur. Kota Ende merupakan Ibukota dari Kabupaten Ende yang terletak dipesisir selatan Pulau Flores.

Kota Ende pada masa lalu menjadi salah satu daerah tujuan para pedagang dan pelayar dari Jawa, Makassar, dan Ternate. Karena menjadi salah satu titik transit para pedagang maka sejarah keagamaan dan kepentingan-kepentingan Kolonialisme bermain di daerah-daerah pelabuhan seperti di Kota Ende. Dimulai perdagangan di pelabuhan kota Ende telah tercatat sejak tahun 1660 yaitu hubungan antara Ende, Raja Makassar dan VOC. Sejak saat itu pihak Belanda (VOC) membangun posthourder Barai di daerah pesisir Teluk Ende (Irshanto, 2016:74).

Pada dasawarsa tersebut, untuk melancarkan usaha di negeri jajahan, pemerintah Kolonial Belanda membangun segala fasilitas sarana dan prasarana yaitu seperti bangunan-bangunan pemerintah, bangunan-bangunan umum, gereja dan bangunan-bangunan sekolah. Bangunanbangunan peninggalan sejarah tersebut masih ada yang bertahan hingga kini dan ada juga yang sudah mengalami perubahan akibat rusak dimakan usia.

Bangunan kolonial di Indonesia merupakan fenomena yang unik, percampuran budaya antara penjajah dan budaya Indonesia yang tidak terdapat ditempat lain (Sumalyo dalam Veronica, 2015), serta disesuaikan dengan kondisi iklimnya yaitu iklim tropis lembab. Bangunan bernilai sejarah yang masih bertahan dan memiliki ciri arsitektur kolonial di Kota Ende, salah satunya adalah bangunan Sekolah Menengah Atas Katolik Syuradikara (SMAK). Sekolah ini beralamat di jalan Wirajaya, Kelurahan Onekore, Kecamatan Ende Tengah. Pada kawasan tersebut dulunya merupakan salah satu kawasan yang menjadi tempat sejarah keagamaan dan kepentingankepentingan Kolonialisme.

Bangunan kolonial di kawasan jalan Wirajaya tersebut, keberadaannya tanpa disadari beradaptasi dengan iklim tropis. Hal ini dikarenakan dari sejarah asal mula penjajahan Belanda yang masuk ke Indonesia dan membangun fasilitas tempat tinggal yang sesuai dengan iklim yang ada di Indonesia agar bangunan dapat beradaptasi dengan lingkungan sekitar. Saat ini bangunanbangunan yang berada pada kawasan jalan Wirajaya tersebut telah banyak mengalami beberapa perubahan dikarenakan faktor usia bangunan menjadi rapuh dan rusak, serta perubahan akibat renovasi.

TEKNOSIAR Volume 14, No.01, April 20 p-ISSN 1907-5197 (versi cetak) e-ISSN 2721-2270 (versi online) 
Bangunan pada kawasan jalan Wirajaya telah beradaptasi dengan iklim setempat yaitu iklim tropis. Karena aspek tropikalitas menjadi hal yang penting pada proses desain bangunan kolonial. Hal ini dikarenakan agar bangunan sesuai dengan kondisi iklim dan lingkungan sekitar sehingga membuat penghuni bangunan nyaman untuk tinggal. Bangunan kolonial yang menjadi tinjauan yaitu bangunan SMAK Syuradikara dengan pendekatan terhadap iklim tropis yang meliputi orientasi bangunan, bukaan dan material yang digunakan.

\section{Arsitektur Kolonial}

Menurut Handinoto \& Soehargo (1996), bahwa arsitektur kolonial Belanda terdiri atas dua periode, yaitu : Arsitektur sebelum abad XVIII dan Arsitektur setelah abad XVIII. Indische Empire Style, adalah suatu gaya arsitektur kolonial yang berkembang pada abad ke 18 dan 19, sebelum terjadinya "westernisasi" pada kota-kota di Indonesia di awal abad ke 20. Gaya ini merupakan hasil percampuran antara teknologi, bahan bangunan dan iklim yang ada di Hindia Belanda dengan gaya Empire Style yang sedang berkembang di Perancis.

Voor 1900. Gaya Voor ini berkembang mulai awal tahun 1900, coraknya hampir sama dengan Indische Empire Style, tetapi mengalami beberapa perubahan pada penggunaan bahan bangunan seperti besi dan terdapat penambahan elemen - elemen yang bertujuan untuk lebih menyesuaikan dengan iklim tropis Indonesia.

NA 1900. Aliran ini dipengaruhi aliran romantis Eropa. Denah yang masih simetris tidak mempengaruhi tampak muka bangunan. Tampak bangunan utama mulai asimetri. Dilengkapi dengan serambi muka terbuka memanjang dengan kolom sudah mulai menghilang/ menyempit diganti dengan penonjolan denah sampai bidang muka bangunan.

Romantiek. Corak arsitektur NA 1900 dengan pengaruh romantik Eropa yang semakin kuat. Penambahan detail dekoratif kaya pada hampir seluruh bagian bangunan dan elemen ruang luar. Elemen bangunan yang membentuk muka bangunan yang membedakan dengan gaya bangunan kolonial yang lain. Ciri-ciri utama adalah banyaknya penggunaan lengkung, bentuk atap tinggi (kemiringan antara $45^{\circ}-60^{\circ}$ ) dengan penutup genting.

Secara umum yang nampak menonjol dari arsitektur kolonial, menurut Hanan (1986) adalah kemampuannya dalam memberikan bukti akan produk arsitektur masa lalu yang tinggi kualitas kebertahanannya (persistence). Bangunan kolonial juga merupakan salah satu contoh dari desain yang adaptif terhadap iklim (Gordon, 1988). Pada dasarnya, arsitektur kolonial dapat dikategorikan dalam tiga kelompok, yaitu bangunan yang belum beradaptasi, baru sebagian beradaptasi, dan sudah beradaptasi dengan iklim tropis lembab (Purwanto, 2004).

\section{Fasade Bangunan}

Fasade merupakan elemen arsitektur terpenting yang mampu menyuarakan fungsi dan makna sebuah bangunan (Krier, 2001). Fasade bukan hanya menyangkut bagaimana cara untuk medapatkan "persyaratan alamie yang ditetapkan oleh organisasi dan ruang dibaliknya. Komponen Fasade adalah representasi atau ekspresi dari berbagai aspek yang muncul dan dapat diamati secara visual.

Menurut Lippsmeier (1980), elemen wajah bangunan yang sekaligus merupakan komponenkomponen yang mempengaruhi fasade bangunan dan dapat dijadikan dasar dalam menganalisis adalah bagian atap, dinding, dan lantai. Selanjutnya Krier (2001) mendetailkan elemen-elemen dari wajah bangunan yang dapat dianalisis menjadi elemen atap, pintu, jendela, kolom, dinding dan lantai. Dalam penelaahan wajah bangunan kolonial, ada hal lain yang harus diperhatikan adalah keberadaan ornamen hias pada setiap elemen bangunan yang biasanya dapat berupa ukiran, motif bentuk dari elemen maupun penambahan bentuk tertentu. Motif-motif tersebut

TEKNOSIAR Volume 14, No.01, April 20

p-ISSN 1907-5197 (versi cetak) e-ISSN 2721-2270 (versi online) 
pada bangunan bergaya kolonial Belanda dapat ditemukan misalnya pada Gable/gevel, Tower/Menara, Ballustrade, Bouvenlicht, Hiasan puncak atap maupun bagian lainnya (Krier, 2001)

\section{Arsitektur Tropis}

Secara harafiah, Arsitektur tropis adalah sebuah produk pemikiran dan budaya yang tumbuh dan berkembang di wilayah iklim tropis. Secara alamiah ia mengalami perkembangan dan pertumbuhan baik secara fisik maupun non fisik seiring dengan pertambahan dan kemajuan waktu, pemikiran, dan teknologi. Adapun kemudian muncul elemenelemen yang berhasil menjadi pokok-pokok elemen arsitektur tropis akan terus diuji dan mengalami formologi, seperti modifikasi atap, ruang teras, ventilasi, tanpa mengurangi fungsi utama dari arsitektur tropis untuk mengatasi masalah iklim tropis.

Ciri-ciri iklim daerah yang terdapat di wilayah indonesia terbagi dalam dua bagian yaitu : 1) Daerah hutan hujan tropis, 2) Daerah hutan hujan khatulistiwa. Karakteristik daerah hutan hujan tropis di daerah tropis basah. Iklim tropis memberikan pengaruh yang cukup signifikan terhadap bentuk bangunan, dalam hal ini khususnya bangunan kolonial. Kondisi iklim seperti temperatur udara, radiasi matahari, angin, kelembaban, serta curah hujan, mempengaruhi desain bangunan kolonial. Konsep bangunan tropis selalu dihubungkan dengan sebab akibat dan adaptasi bentuk bangunan terhadap iklim, (Lippsmeier, 1980).

Kondisi iklim tropis memerlukan syarat-syarat khusus dalam perancangan bangunan dan lingkungan binaan, mengingat ada beberapa faktorfaktor spesifik yang hanya dijumpai secara khusus pada iklim tersebut, sehingga teori-teori arsitektur, komposisi, bentuk, fungsi bangunan, citra bangunan dan nilai-nilai estetika bangunan yang terbentuk akan sangat berbeda dengan kondisi yang ada di wilayah lain yang berbeda kondisi iklimnya.

Ada beberapa prinsip dalam desain banguinan di iklim tropis :

1) Bukaan yang banyak, untuk mengatasi permasalahan suhu ruangan yang harus sesuai dengan yang dibutuhkan, selain sebagai sirkulasi udara. Dapat berupa jendela-jendela yang besar, pintupintu yang lebar ataupun meletakkan sedikit taman terbuka di dalam rumah.

2) Suhu udara yang tinggi dapat pula dinetralisir dengan memasukkan unsur air ke dalam rumah, seperti adanya kolam atau air mancur mini.

3) Pemanfaatan sinar matahari di siang hari sebagai sumber cahaya utama, dengan pengaplikasian skylight atau lubang bukaan cahaya pada bagian atas maupun dinding bagian atas.

4) Permainan façade bangunan untuk mengatur arah jatuhnya sinar matahari, terutama di sore dan pagi hari dimana sudut jatuh sinar matahari kecil.

5) Menggunakan material bangunan yang alami yang tampak ringan, seperti batu alam, batu expose atau kayu.

6) Ventilasi silang adalah menciptakan perbedaan tekanan udara sehingga udara bisa mengalir. Ventilasi ini bisa berupa jendela, pintu, lubang angin. Yang intinya untuk lubang keluar masuk udara dari luar ruangan. Bukaan ventilasi yang tepat sangat penting bagi kenyamanan ruang. Ventilasi yang baik memungkinkan terjadinya aliran udara selama 24 jam tanpa bantuan peralatan mekanis.

\section{METODE}

Metode yang digunakan dalam kajian ini adalah kualitatif deskriptif. Metode kualitatif deskriptif digunakan untuk menguraikan elemen bangunan SMAK Syuradikara yang berkaitan erat dengan iklim tropis. Tujuan dari kajian deskriptif ini adalah untuk mendeskripsi, gambaran atau lukisan secara sistematis, faktual dan akurat mengenai fakta-fakta, sifat-sifat serta hubungan antar fenomena yang diselidiki (Groat \& Wang, 2002).

TEKNOSIAR Volume 14, No.01, April 20

p-ISSN 1907-5197 (versi cetak) e-ISSN 2721-2270 (versi online) 
Langkah awal dalam kajian ini, yaitu melakukan observasi lapangan atau kegiatan survei pada objek dan pengumpulan data sekunder mengenai obyek tersebut. Hasil dari observasi digunakan untuk mendapatkan gambaran dari objek. Setelah mengetahui gambaran tersebut, selanjutnya mendeskripsikan tiap elemen pada bangunan SMAK Syuradikara dengan pendekatan arsitektur tropis.

\section{HASIL DAN PEMBAHASAN}

\section{Perjalanan Singkat Lahirnya SMAK Syuradikara}

Sejak awal tahun 1948, telah direncanakan untuk mendirikan sebuah Sekolah Menengah Atas di Ende, Flores. Rencana tentang akan didirikan Sekolah Menengah Atas di Ende tersebut tercatatat dalam surat bahasa Belanda, tertanggal 10 Februari 1948. Surat itu dikirimkan oleh Superior Generalis SVD yang berkedudukan di Roma, ditujukan kepada Pater Regional Anton Thijssen di Ende Flores. Surat tersebut berisi jawaban terhadap surat Mgr. A. Thijssen tertanggal 28 Januari 1948 tentang pendirian SMA. Itulah surat pertama dari Roma menjawab surat pertama dari Ende, yang memberi tanda dimulainya pikiran - pikiran maju tentang sebuah sekolah baru.

Pada tanggal 6 Januari 1953, P. Schouten SJ menulis surat kepada Mgr. A. Thijssen. Isinya menjelaskan bahwa pemerintah, dalam hal ini Kementrian Pendidikan, Pengajaran, dan Kebudayaan belum bermaksud serta belum bisa membuka SMA Negeri di Flores. Hal ini dapat dimaklumi karena Republik Indonesia baru berusia 8 tahun. Satu SMAN untuk satu provinsi masih dianggap cukup. Anggaran pembangunan tersebar untuk berbagai sektor. Siswa-siswi yang berminat melanjutkan pendidikan ke SMA diarahkan untuk bersekolah di Kupang atau SMA lainnya di Jawa.

Ketiadaan biaya dari Pemerintah, bukan berarti perjalanan sudah berakhir. Langkah kongkrit ditempuh melalui berbagai persiapan untuk terlibat langsung dalam pemberdayaan pendidikan anakanak pada wilayah pengabdian SVD. Dan pada tanggal 24 Januari 1953, P. Regional E. Kuhne dan Kuasa Usaha Pengurus Persekolahan Katolik di Flores, P. Fransiskus Cornelissen mengeluarkan sebuah surat maklumat tentang akan didirikannya sebuah SMA Katolik di Ende.

Maklumat yang dikeluarkan mendapat reaksi luas di kalangan masyarakat Flores dan Ende khususnya. Gaung akan berdirinya SMAK Syuradiakara membuat kota Ende menjadi lebih hidup. Maklumat itu berisi adanya sebuah sekolah SMA Katolik di Ende demi kepentingan pendidikan di wilayah Flores secara umum. Maka Serikat Sabda Allah (SVD) mendirikan sebuah SMA di kota Ende yang diresmikan pada tanggal 01 September 1953 dengan nama "SMAK SYURADIKARA", yang berarti "PENCIPTA PAHLAWAN UTAMA", dalam bahasa Sanskrit. Pater Yohanes Ebben, SVD adalah Kepala SMA Katolik yang pertama.

\section{Fasilitas dan Fungsi Ruang}

Sejak awal berdirinya SMAK Syuradikara yang terletak di jalan Wirajaya, Kelurahan Onekore, Kecamatan Ende Tengah, Kabupaten Ende, Provinsi Nusa Tenggara Timur ini sudah hadir sebagai simbol prestasi akademik. Semua lapangan olahraga tersedia, mulai dari basket, voli, sampai sepak bola. Aulanya berkapasitas 1.000 orang. Fasilitas tersebut untuk mendukung berbagai macam kegiatan ekstrakurikuler seperti pramuka, mercing band, atletik, maupun pertandingan bola kaki.

Fasad bangunan menerapakan konsep keseimbangan, dimana sisi terpanjang bangunan menghadap ke arah jalan utama. Sehingga fasad bangunan secara keseluruhan menjadi terlihat jelas. Denah bangunan sangat sederhana, cenderung berbentuk simetris, dengan bentuk denah empat persegi panjang. Bentuk bangunan dominan menggunakan konstruksi atap yang bersudut 3045 derajat. Hal ini terlihat pada bentuk atap bangunan maupun pada atap teras utama. Tinggi bangunan dibuat sangat tinggi, mencapai 3-4 kali tinggi manusia.

TEKNOSIAR Volume 14, No.01, April 20

p-ISSN 1907-5197 (versi cetak) e-ISSN 2721-2270 (versi online) 
Jumlah ruang kelas ada 32 ruangan untuk proses KBM (Kegiatan Belajar Mengajar). Laboratorium ada 3 ruangan, untuk kegiatan penelitian, maupun percobaan ilmiah serta perpustakaan guna meningkatkan minat baca siswa. Ada pemisahan antara ruang kelas, ruang guru, dan ruang kesiswaan. Masing-masing ruang mempunyai fungsi maupun kegiatan yang berbeda. Semua fasilitas sekolah tersebut berada diatas tanah seluas 95.534

\section{Orientasi Bangunan}

\section{Orientasi Terhadap Matahari}

Orientasi bangunan secara keseluruhan menghadap dan memanjang kearah utara (tampak depan) dan selatan (tampak belakang). Sehingga sisi terpendek permukaan bangunan yang menghadap arah datangnya dan terbenamnya matahari (timur-barat), hanya sedikit yang menerima panas matahari. Bagian permukaan dinding yang sedikit (sisi terpendek) terkena sinar matahari secara langsung. Ada beberapa bangunan lain, yang sisi terluasnya langsung menghadap ke arah datangnya matahari, seperti ruangan kelas sehingga ruangan tersebut menerima sinar matahari pagi secara langsung. Efek orientasi bangunan terhadap suhu udara di dalam bangunan tersebut juga nampak jelas. Suhu ruangan rata-rata pada sisi dinding timur dan barat lebih tinggi dibanding suhu ruangan pada sisi utara dan selatan.

\section{Orientasi Terhadap Angin}

Aliran angin di sekitar bangunan datang dari arah timur dan barat, aliran angin tersebut relatif normal atau tidak terlalu kencang. Disekitar bangunan terdapat pepohonan yang tidak terlalu tinggi, hal ini cukup membantu sirkulasi aliran angin ke dalam ruangan. Ruangan yang mendapatkan aliran angin yang baik adalah ruang kelas dan beberapa ruang lainnya yang menghadap langsung ke arah datangnya aliran angin (timur dan barat).

\section{Bukaan (Ventilasi)}

Posisi bukaan diberi jarak yang cukup dari dinding terluar sehingga penutup atap dapat melindungi sinar matahari dan tidak dapat langsung masuk kedalam ruangan. Jendela (ventiasi tengah) menggunakan bingkai kayu, kaca, dan kombinasi trali yang menyerupai jaring dengan bentuk yang bervariasi. Orientasi peletakan jendela lebih dominan menghadap ke arah utara dan selatan. Posisi ini cukup baik karena tidak mendapat sinar matahari secara langsung. Ukurannya 30 sampai 50 centimeter. Ukurannya tergolong kecil. Bentuk jendelanya horizontal dengan jumlah 16 buah pada bagian sisi kiri dan sisi bagian kanan 12 buah.
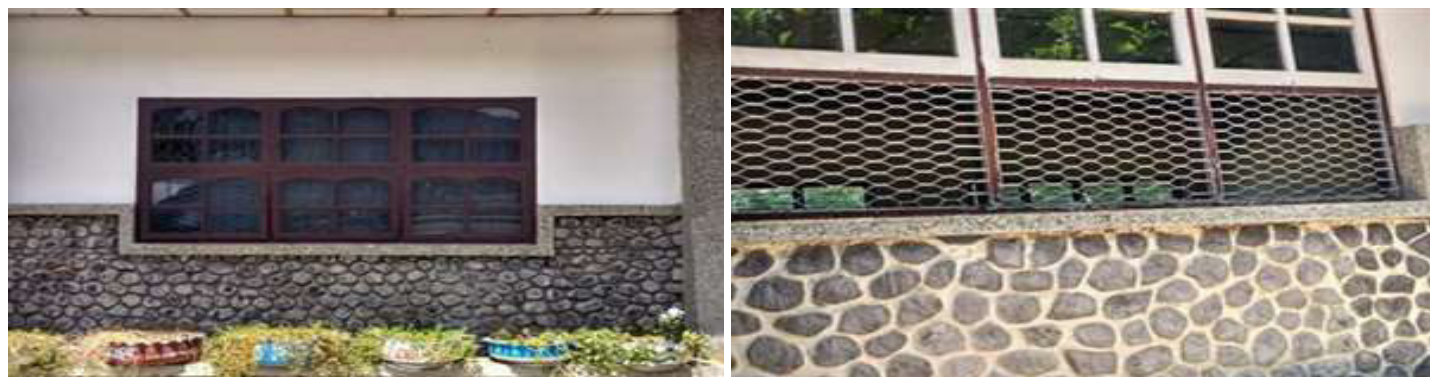

Gambar 1. Jendela pada bangunan SMAK Syuradikara

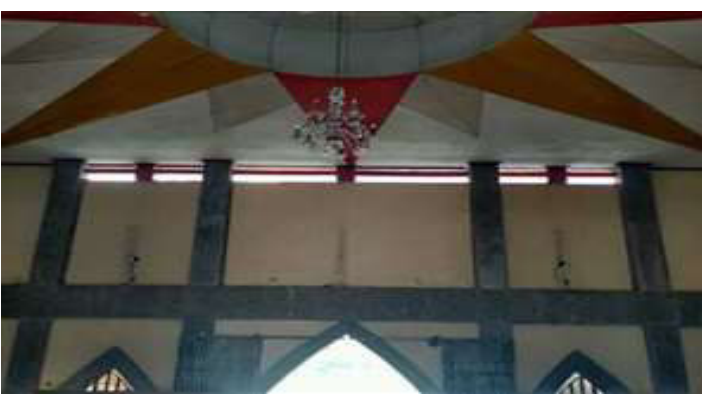

Gambar 2. Ventilasi yang letaknya paling atas, ada 8 buah.

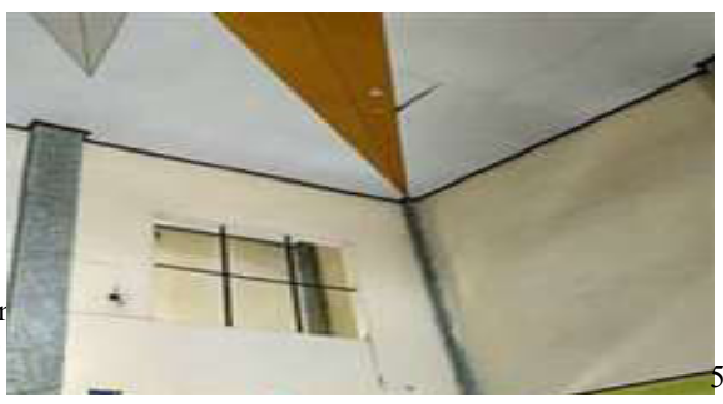

Gambar 3. Ventilasi yang letaknya di atas, ada 4 buah. 


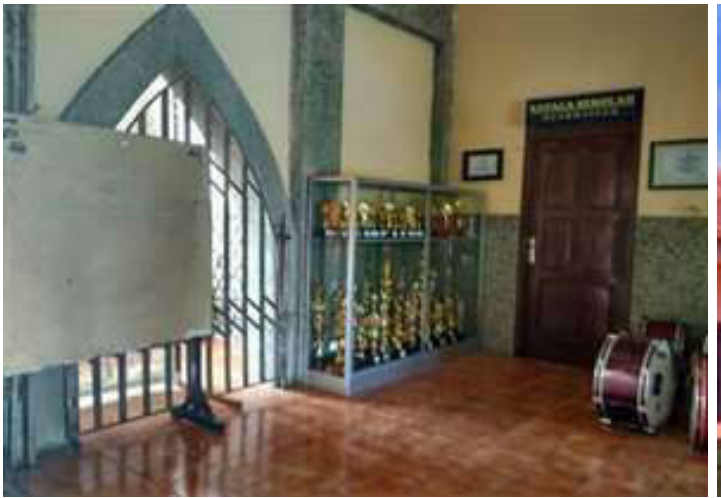

Gambar 4. Ventilasi dengan bentuk seperti kubah, ada 2 buah.

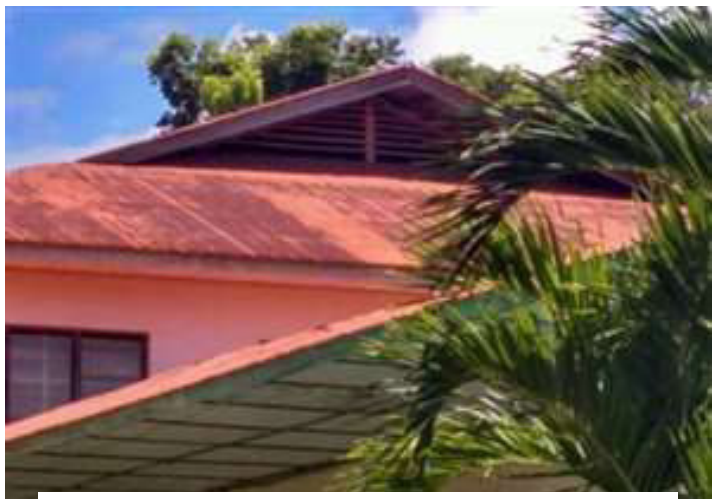

Gambar 5. Ventilasi atap, ada 1 buah.

Ventilasi atas diletakan pada posisi arah utara dan selatan, yang fungsinya untuk pertukaran udara bersih dan kotor dari dalam ruangan ke luar ruangan. Ukurannya beragam, ada yang kecil dengan lebar 10 centimeter. Ada yang sedang dengan lebar 50 centimeter, diletakan secara horizontal dan ukuran besar dengan lebar dan tinggi 80 centimeter, kategori bentuk vertikal.

Adaya ventilasi udara pada bagian sebelah sisi barat atap (antara atap dan langit-langit). Letaknya tepat mengarah pada arah datangnya aliran angin dari timur maupun barat. Jumlahnya 1 buah, tinggi 40 centimeter, menggunakan jalusi dari kayu dengan posisi horizontal. Ventilasi udara ini (ventilasi atap) bertujuan untuk pertukaran udara, sehingga tidak terjadi akumulasi panas pada ruang tersebut. Ventilasi atap ini sangat membantu pencapaian suhu ruangan yang rendah.

\section{Teras (Serambi)}

Pada bangunan terdapat teras (serambi) yang berfungsi sebagai koridor (lorong) untuk sirkulasi jalan dengan ukuran berkisar antara 1 sampai 2 meter. Teras terletak di arah utara, timur, barat dan selatan berjumlah 4 buah, membentuk persegi. Teras dibuat sepanjang bangunan untuk mengantisipasi sinar matahari langsung yang mengenai dinding bangunan, serta hempasan dari air hujan. Pada sisi arah selatan, bentuk teras dibuat melengkung dan ditopang oleh deretan kolom dari beton sehingga menambah kesan estetika. Lebarnya 1 meter, dengan jumlah 2 buah.

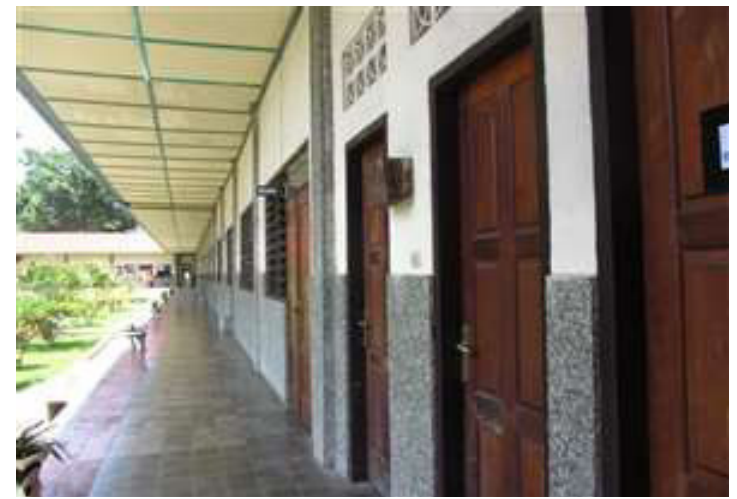

Gambar 6. Teras terletak di arah utara, timur, barat

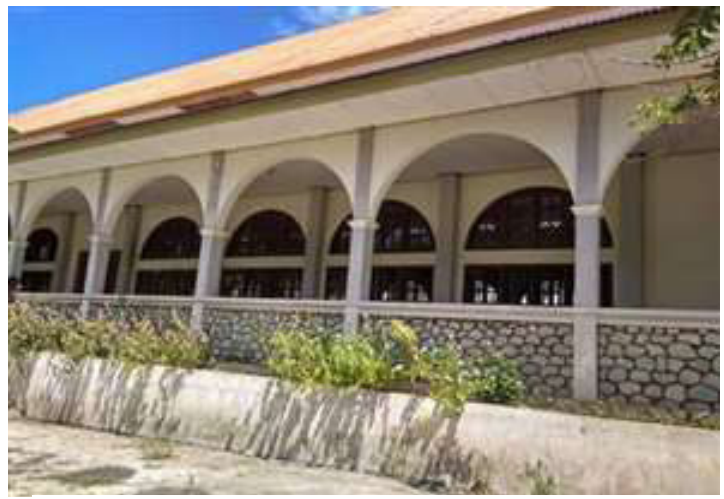

Gambar 7. Teras melengkung, arah selatan 
Pada teras dibuat tembok sebagai pembatas dengan taman, sekaligus sebagai penghalang sinar matahari. Arah utara, terdapat kanopi dengan panjang 3 meter dan lebar $30 \mathrm{~cm}$, jumlahnya 1 buah. Bentuk persegi panjang dan terbuat dari bata merah dan dilapisi dengan keramik berukuran $15 \times 10$ centimeter. Kanopi ini berfungsi sebagai pembayangan yang ditempatkan melekat pada bangunan secara vertikal dan horizontal.
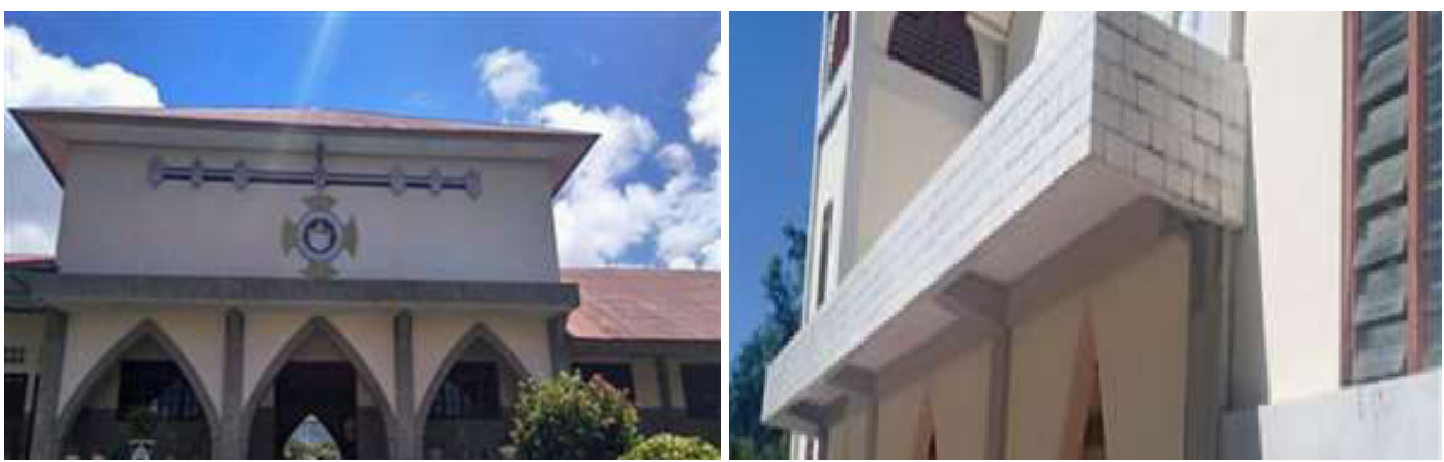

nopi, berfungsi sebagai pembayangan

\section{Material pada Bangu}

Material lantai dari keramik dan tegel yang belum dipoles dengan permukaan sedikit kasar, ukuran $30 \times 30 \mathrm{~cm}$. Lantai jenis ini bismenyerap panas, sehingga rang yang ada cenderung lebih dingin, selain itu juga kedap air dankeras. Ada perbedaan ketinggian lantai luar dengan lantai dalam, tujuannya untuk dapat mengurangi debu yang terbawa dari angin luar. Rata-rata ketinggian lantai dari permukaan adalah 30 sampa 60 centimeter.
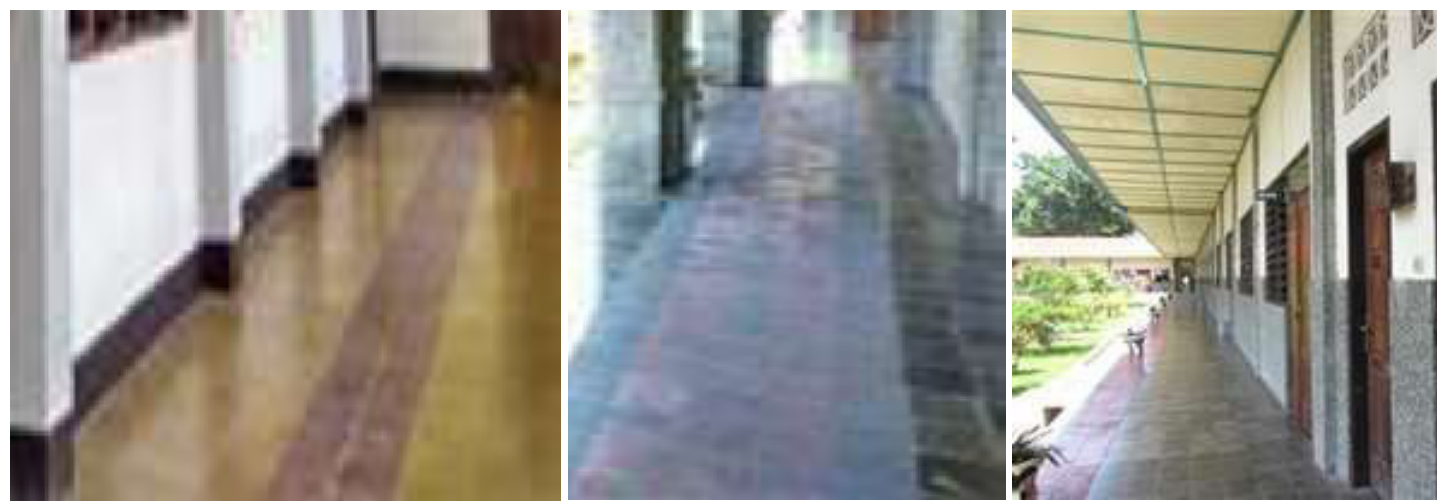

Gambar 9. Lantai dari keramik dan lantai tegel
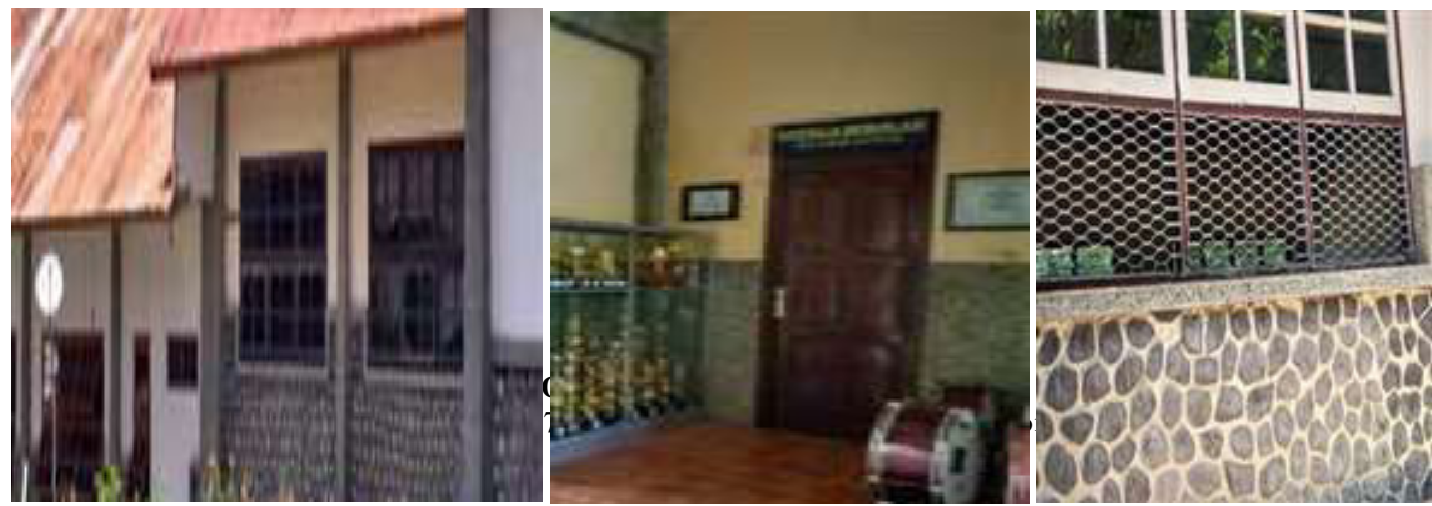

Gambar 10. Dinding bata yang diplester, dan dilapisi batu kali. 

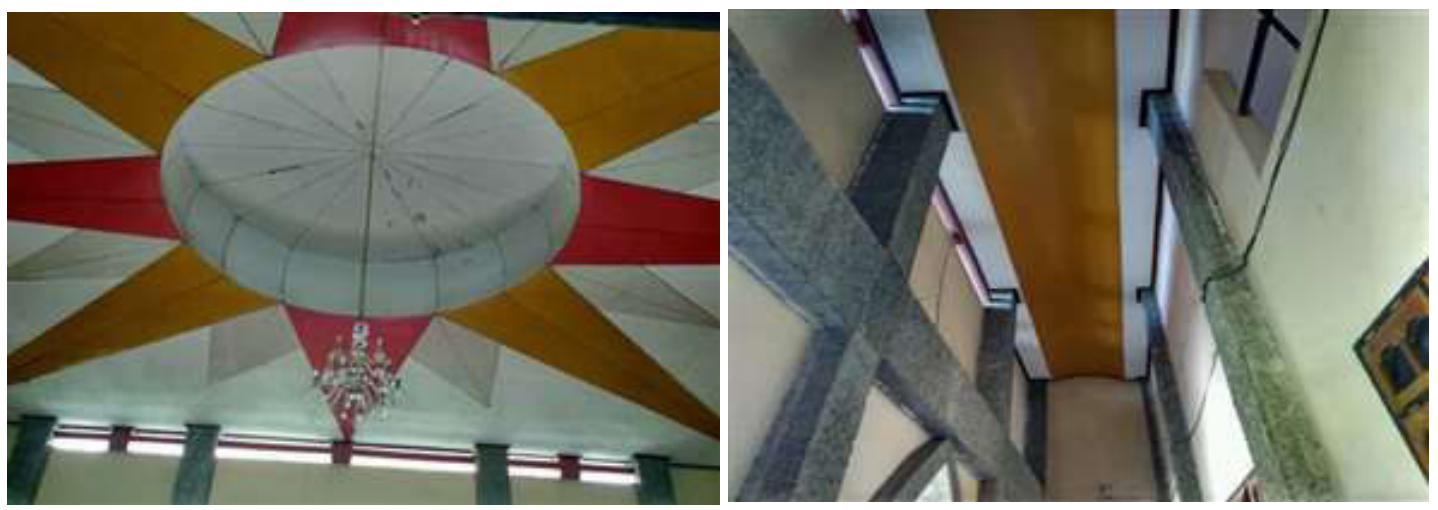

Gambar 11. Plafon dari triplek yang dimodifikasi.

Dinding pada bangunan merupakan dinding pemikul yang terbuat dari susunan bata yang diplester, tebal dinding antara 30 sampai 40 centimeter. Ketebalan dinding merupakan salah satu solusi dalam mereduksi udara panas yang ada dalam ruangan. Semakin tebal bidang dinding semakin tinggi kemampuan permukaan dinding dalam mereduksi panas. Ada juga dinding dari bata tetapi pada sisi luar dilapisi batu kali. Lapisan batu kali berukuran lebar $1 \mathrm{~cm}$ sampai $8 \mathrm{~cm}$, tebal 0,3 sampai $1,5 \mathrm{~cm}$ dengan warna abu-abu dan hijau.

Plafon terbuat dari triplek yang dimodifikasi sehingga nampak berestetika. Bentuknya simetris dengan paduan warna yang menarik. Tinggi plafon (ruangan) dibuat sangat tinggi, dapat mencapai 3-4 kali tinggi manusia. Tingginya plafon (ruangan) tersebut menyebabkan dibuatnya lampu-lampu gantung sebagai penerangan dalam ruangan.

\section{KESIMPULAN}

Dari hasil kajian ini dapat kita ambil beberapa kesimpulan yang berkaitan dengan pendekatan arsitektur tropis yang diterapkan pada bangunan SMAK Syuradikara adalah sebagai berikut:

1. Orientasi bangunan secara keseluruhan menghadap dan memanjang kearah utara dan selatan. Sehingga sisi terpendek permukaan bangunan yang menghadap arah datangnya dan terbenamnya matahari (timur-barat) hanya sedikit yang menerima panas matahari.

2. Aliran angin di sekitar bangunan datang dari arah timur dan barat. Ruangan yang mendapatkan aliran angin yang baik adalah ruang kelas dan beberapa ruang lainnya yang menghadap langsung ke arah datangnya aliran angin (timur dan barat).

3. Orientasi peletakan jendela lebih dominan menghadap ke arah utara dan selatan. Posisi ini cukup baik karena tidak mendapat sinar matahari secara langsung.

4. Ventilasi atas diletakan pada posisi arah utara dan selatan, yang fungsinya untuk pertukaran udara bersih dan kotor dari dalam ruangan ke luar ruangan. Adanya ventilasi udara pada bagian sebelah sisi barat atap (antara atap dan langit-langit). Letaknya tepat mengarah pada arah datangnya aliran angin dari timur maupun barat.

TEKNOSIAR Volume 14, No.01, April 20

p-ISSN 1907-5197 (versi cetak) e-ISSN 2721-2270 (versi online) 
5. Teras dibuat sepanjang bangunan untuk mengantisipasi sinar matahari langsung yang mengenai dinding bangunan, serta hempasan dari air hujan.

6. Material lantai dari keramik dan tegel yang belum dipoles dengan permukaan sedikit kasar. Lantai jenis ini bisa menyerap panas, sehingga ruang yang ada cenderung lebih dingin, selain itu juga kedap air dan keras.

7. Dinding bangunan terbuat dari susunan bata yang diplester, tebal dinding antara 30 sampai 40 centimeter. Ketebalan dinding salah satu solusi dalam mereduksi udara panas yang ada dalam ruangan.

\section{DAFTAR PUSTAKA}

Groat, L. \& Wang, D, 2002. Architectural Research Methods. New York: John Wiley \& Sons. Inc. Hadinoto. 2010. Arsitektur dan Kota-kota di Jawa pada Masa Kolonial. Grahallmu. Yogyakarta.

Krier, R. 2001 . Komposisi Arsitektur, Erlangga, Jakarta.

Lippsmeier, G. 1980. Bangunan Tropis (Edisi ke-2). Erlangga, Jakarta.

Gordon, Alex (1988), Simposium IAI : Change and Heritage in Indonesia Cities, Konstruksi, Jakarta.

Kumuru, Veronica A. (2015). Pengaruh Gaya Arsitektur Kolonial Belanda pada Bangunan Bersejarah di Kawasan Manado Kota Lama. Prosiding Temu Ilmiah IPLBI 2015.

Purwanto, L.M.F. (2004), Kenyamanan Termal pada Bangunan Kolonial Belanda di Semarang, Jurnal Dimensi Teknik Arsiteklur, Volume 32, Nomor 2, Desember.

TEKNOSIAR Volume 14, No.01, April 20

p-ISSN 1907-5197 (versi cetak) e-ISSN 2721-2270 (versi online) 